\title{
Reflexões sobre o papel da escola e da profissionalidade na modalidade de educação especial: das exigências formais à pessoalidade
}

\author{
Jacqueline Lidiane de Souza Prais \\ Universidade Tecnológica Federal do Paraná - Campus Londrina (UTFPR/LD) \\ Juliana Irani Villanueva dos Reis \\ Universidade Tecnológica Federal do Paraná - Campus Londrina (UTFPR/LD) \\ Daniel Guerrini \\ Universidade Tecnológica Federal do Paraná - Campus Londrina (UTFPR/LD)
}

\begin{abstract}
Resumo
Este trabalho aborda o papel da escola e do trabalho pedagógico na Educação Especial, destacando o conceito de profissionalidade docente nessa modalidade de ensino. Nessa perspectiva, apresenta e analisa os discursos pedagógicos de professores que atuam na Escola de Educação Básica na modalidade de Educação Especial acerca de seu trabalho docente junto aos alunos com deficiência. Para tanto, emprega a revisão bibliográfica e a pesquisa de campo como metodologia de pesquisa, com aplicação de questionários como instrumento de coleta de dados empíricos. Dentre os resultados, destaca que, diante da sua prática pedagógica, os professores participantes da pesquisa elencaram aspectos de suas relações privadas como requisitos necessários para atuação nessa modalidade de ensino, o que os distancia das exigências formais da constituição de uma profissionalidade docente. Espera-se oferecer uma contribuição ao campo temático do trabalho docente na Educação Especial e o trabalho pedagógico na educação de pessoas com deficiência.

Palavras-chave: Trabalho docente; Escola; Educação Especial; Profissionalidade.
\end{abstract}

\begin{abstract}
This paper discusses the role of the school and of pedagogical work in Special Education, pointing out the concept of teacher professionalism in this modality of teaching. In this perspective, we present and analyze the pedagogical discourses of teachers who work in Basic Education Schools in the Special Education modality, concerning their pedagogical work with disabled students. For this purpose, the research methodology combined the bibliographical review and field research, applying questionnaires as the instrument of empirical data collection. The results show that, from their pedagogical practice, the participant teachers highlight that some of the aspects of their personal relationships are a necessary condition for teaching in this modality. However, this suggests a distance between the participants and the formal demands on teachers as professionals. This paper hopefully offers a contribution to the thematic field of teacher's work in Special Education and in pedagogical work for the education of disabled people.
\end{abstract}

Keywords: Teacher work; School; Special Education; Professionalism. 


\section{INTRODUÇÃO}

A Educação Especial é uma modalidade de ensino destinada aos alunos com deficiência, transtornos globais de desenvolvimento e com altas habilidades/superdotação, perpassando todos os níveis e etapas de ensino no sistema educacional brasileiro (BRASIL, 1996). Ainda, notamos o uso da nomenclatura de alunos com Necessidades Educacionais Especiais $(\mathrm{NEE})^{1}$ para referenciar alunos com deficiência ou dificuldade de aprendizagem. Dentre os serviços e apoios educacionais especializados que são previstos nessa modalidade para escolarização de alunos público-alvo da Educação Especial há as escolas especiais.

Segundo as Diretrizes Nacionais para a Educação Especial na Educação Básica (BRASIL, 2001) em seu artigo $10^{\circ}$, as escolas especiais representam, "em caráter extraordinário", o atendimento a alunos com NEE e que, consequentemente necessidade de “ajudas e apoios intensos e contínuos, bem como adaptações curriculares significativas". Dessa forma, as escolas especiais consistem em um atendimento que substitui a escolarização ofertada no ensino regular a fim de garantir a educação escolar e promover as potencialidades dos alunos com NEE.

No Estado do Paraná, essas instituições são denominadas de Escola de Educação Básica na modalidade de Educação Especial ${ }^{2}$, que consiste numa instituição de ensino, exclusiva, "[...] para alunos com necessidades educacionais especiais, com graves comprometimentos, múltipla deficiência ou condições de comunicação e sinalização diferenciadas" (PARANÁ, 2003, p. 6).

A esse propósito, ambos os documentos, as Diretrizes Nacionais (BRASIL. 2001) e as normas estaduais (PARANÁ, 2003) para as escolas especiais, enfatizam que esse processo de escolarização promovido nessas instituições de ensino devem garantir as especificidades de um atendimento educacional especializado em função das condições peculiares dos alunos.

Nesse contexto, apontamos que a política nacional de educação inclusiva prevê que essas escolas devam oferecer atendimento educacional especializado no contra turno ao do ensino regular em que o aluno público-alvo da Educação Especial está matriculado. Essa perspectiva defende que todos tenham acesso ao ensino regular e a uma rede de apoio, na qual se enquadram as "escolas especiais" ou centros de apoios especializados.

\footnotetext{
1 “[...] refere-se a todas aquelas crianças ou jovens cujas necessidades educacionais especiais se originam em função de deficiências ou dificuldades de aprendizagem” (BRASIL, 1994, p. 3).

${ }^{2}$ Nomenclatura dada às escolas especiais no estado do Paraná, conhecidas como "APAES”, a partir da Resolução $\mathrm{n}^{\mathrm{o}} 3600 / 2011$.
} 
No entanto, convém destacar que nessa investigação, optamos por identificar os discursos pedagógicos de docentes que atuam em uma escola municipal de Educação Básica na modalidade de Educação Especial do Estado do Paraná que, contrário à política educacional nacional de inclusão, mantém essas escolas em caráter de substituição à escolarização no ensino regular (PARANÁ, 2006).

Tendo em vista tais prerrogativas supracitadas, realizamos um estudo sobre o papel dessa instituição e do trabalho pedagógico na Educação Especial, enfatizando a profissionalidade docente nessa modalidade de ensino. Ainda a esse respeito, apresentamos os entendimentos dos professores que atuam na escola de Educação Básica na modalidade de Educação Especial acerca de seu trabalho pedagógico junto aos alunos com deficiência. Esses dois pontos de discussão representam, respectivamente, as seções deste artigo, somados a análise e discussões dos resultados.

Assim, este artigo se norteia pela seguinte questão de investigação: quais as compreensões de docentes da escola de Educação Básica na modalidade de Educação Especial sobre o seu trabalho com os alunos com deficiência?

Empregamos como encaminhamento metodológico a revisão bibliográfica e a pesquisa de campo, tendo como instrumento de coleta de dados um questionário e como sujeitos da pesquisa vinte (20) professores de duas escolas municipais de Educação Básica na modalidade de Educação Especial localizadas em um município do norte do Paraná.

O ponto de partida são as concepções de Libâneo (2004) quanto aos conceitos de profissionalidade, de profissionalização e de profissionalismo; Ferreira (1993), Bourdieu (1966) e Bourdieu e Passeron (2013) sobre o papel da escola e do trabalho docente; bem como, as diretrizes e normas para Educação Especial no estado do Paraná $(2003$; 2014).

A questão investigativa e objetivos específicos dessa pesquisa, mencionados acima, são relevantes devido à compreensão adequada ao trabalho docente junto aos alunos com deficiência em articulação com determinações legais e entendimentos do ato educativo no processo de escolarização dos alunos. A esse propósito, levamos em consideração também os encaminhamentos pedagógicos necessários ao ensino nessa instituição, para que promovam a aprendizagem dos alunos com deficiência, que, por sua vez, foram desconsiderados do processo educativo escolar em que foram negados seus direitos constitucionais ao acesso e permanência na educação. 


\section{O PAPEL DA ESCOLA E DO TRABALHO DOCENTE: REFLEXÕES SOBRE A EDUCAÇÃO ESPECIAL}

Discutimos nessa seção o papel da escola e do trabalho pedagógico na Educação Especial, destacando o papel do profissional docente nessa modalidade de ensino. Inicialmente, pontuamos algumas reflexões que consideramos relevantes para entendermos as diferenças do processo de socialização e educação, aspectos profissionais da atividade docente, bem como, sobre a escola como espaço educativo que pressupõe um arsenal de técnicas e instrumentos para a escolarização.

Ferreira (1993) afirma que a socialização se refere ao processo de humanização dos sujeitos no qual ele se apropria da cultura historicamente construída sendo ela primária e secundária. A primeira se refere às experiências da infância em que apreendemos elementos da interação humana com objetivos implícitos, e interiorizamos normas e valores dados pelos familiares. Já num segundo momento passa a ser realizada após a infância quando as normas e valores passam a ser entendidas pela criança como construção coletiva. As crianças passam a participar de instituições que envolvem este aprendizado supracitado, que, em sua maioria, é realizado por pessoas especializadas.

De acordo Ferreira (1993), na modernidade, a escola ficou responsável em transmitir para os sujeitos as caraterísticas que sejam essenciais à vida coletiva que se refere ao processo de socialização secundária. Cabe destacar que a educação tem intencionalidade, é sistematizada e tem objetivos explícitos para a formação humana a fim de que se aproprie do que é mais relevante para cada sociedade.

É nas sociedades modernas que se enfatiza a necessidade de um local especializado em ensinar as características essenciais à vida coletiva, denominado escola. Nesse sentido é que a escola, ou seja, a educação assume na modernidade papel essencial para humanização do homem, promovido por especialistas e que certifica o conhecimento adquirido nesse processo para a inserção no mundo do trabalho. Ao mesmo modo em que percebemos uma individualização do processo que permite a especialização do conhecimento, a coletividade passa a ser regida por tais normas e valores sociais perpassados pela escola (FERREIRA, 2003).

De acordo com Tozoni-Reis (2010), a escola na modernidade passa a ter a incumbência de formar a humanidade. Para tanto, deve ensinar os conhecimentos humanos construídos ao longo de seu percurso histórico, social e cultural. Nesse sentido, o professor é a figura do especialista responsável em fazer com que a escola cumpra com sua função social. 
Nesse contexto, a sociedade moderna tem profissionais especializados (professores) responsáveis pela educação das crianças e adolescentes de uma sociedade, e, consequentemente, exige destes profissionais conhecimentos específicos que nortearão seu trabalho.

Como destacam Bourdieu e Passeron (2013), a responsabilidade pela educação exige também do docente uma didática específica. São necessárias técnicas profissionais que se afastem do modelo mistificado do "mestre", alguém que domina conteúdos e mantém uma relação desprendida com o aprendizado e o conhecimento.

Uma das grandes críticas desses autores (não apenas à esfera educacional) é a separação comum que se faz entre trabalho intelectual e manual, como se a docência, a didática ou a pesquisa não exigissem igualmente técnicas manuais, tanto quanto as intelectuais. Os apontamentos que esses autores fazem acerca da sistemática específica e racional, capaz de atingir objetivos claros no processo educativo, têm em vista a incorporação, como habitus, do conhecimento e das técnicas de sua apreensão pelo docente. Essa incorporação passa pelo reconhecimento de que os saberes e o aprendizado pressupõem disciplina, escrita e leitura sistemáticas e memorização, técnicas essas que necessitam ser transmitidas explicitamente pelo docente.

Nessa perspectiva, Libâneo (2004) destaca que ao profissional se subentende um processo formativo necessário para apropriação de conhecimentos técnicos e científicos sobre sua atuação, em caráter público, em instituições especializadas para tal exigência. A esse “conjunto de requisitos profissionais que tornam alguém um professor" (LIBÂNEO, 2004, p. 75) define o conceito de profissionalidade docente.

Ainda, dado às especificidades de sua profissão, esses conhecimentos se diferem de outros profissionais, o que assegura um tipo de conhecimento e desempenho específicos da profissão docente "ligados a um grupo social regulado por princípios éticos e políticos que explicitem e sistematizem os saberes adquiridos e desenvolvidos em conhecimento e em formação" (PARCHEN, 2008, p. 4).

Segundo Libâneo (2004), a profissionalidade diante do processo de formação do profissional docente abarca as categorias de profissionalização e profissionalismo (ver figura 1): a profissionalidade se refere a um conjunto de requisitos que caracterizam a docência, a profissionalização diz respeito ao contexto e processo formativo para a prática pedagógica e o profissionalismo agrega o domínio de técnicas e métodos, atuação e exercício profissional. 
Tais exigências profissionais ao docente são definidas pela categoria e asseguram o exercício e compromisso necessário e de qualidade, bem como estão expressas nas determinações legais que normatizam o ensino.

Figura 1: Conceitos de profissionalidade, profissionalização e profissionalismo

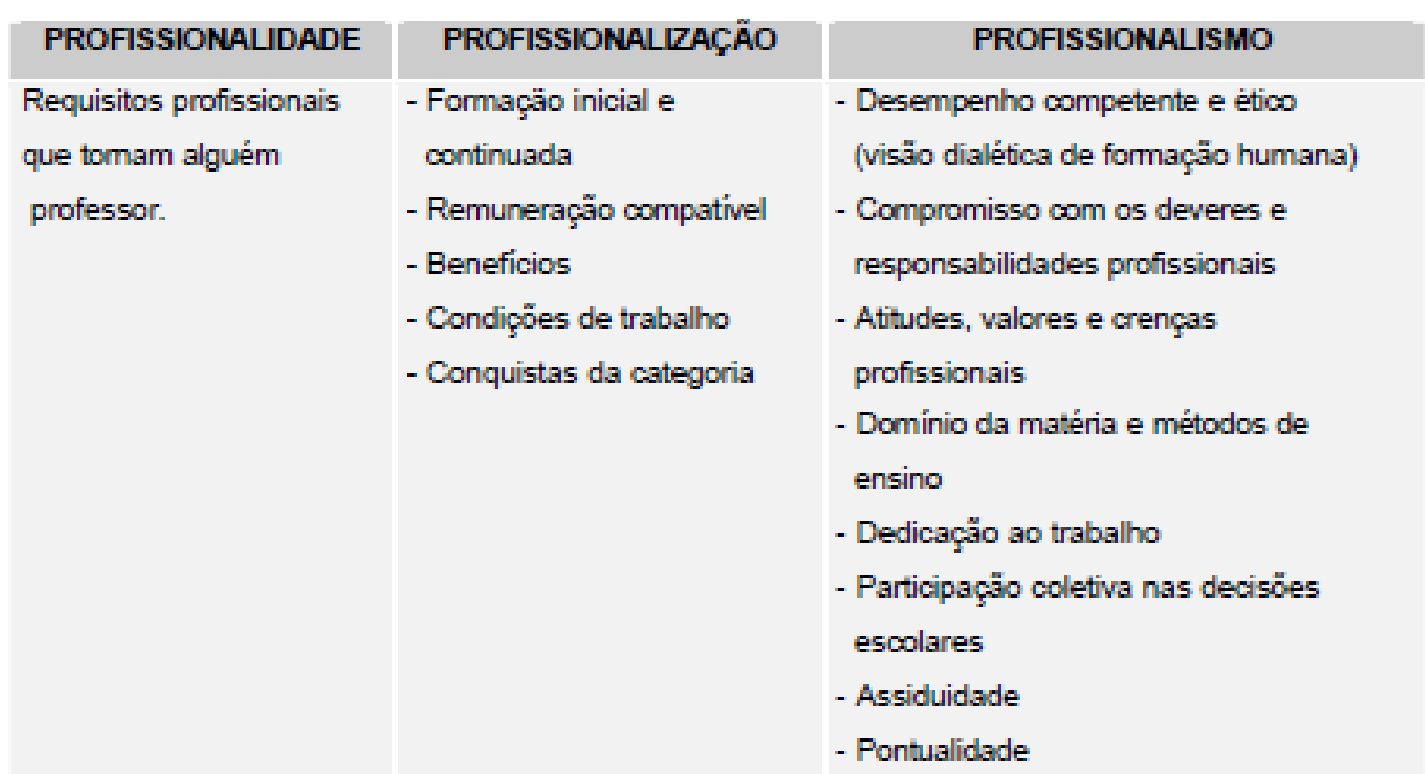

Fonte: Elaborado por Parchen (2008) a partir dos estudos desenvolvidos por Libâneo (2004)

Nesse estudo, delimitamos a apresentação destes pressupostos e requisitos profissionais para o profissional que atua na Escola de Educação Básica na modalidade da Educação Especial. Nesse caso, escolhemos a realização no Estado do Paraná em uma das escolas municipais oferecidas nessa modalidade, considerando que:

[...], apesar de tendências contrárias a esse posicionamento no contexto nacional, optou (O Estado do Paraná) pela permanência das classes especiais e instituições especializadas em sua rede de apoio, entendendo que algumas crianças, jovens e adultos com graves comprometimentos e problemas no desenvolvimento não apresentarão as mesmas condições de aprendizagem acadêmica formal dos demais alunos, necessitando de propostas curriculares alternativas em natureza e finalidade àquelas desenvolvidas pela escola regular (PARANÁ, 2006, p.55).

Nesse contexto, utilizamos três documentos norteadores e normatizadores: em nível nacional, as Diretrizes Nacionais para Educação Especial na Educação Básica (BRASIL, 2001), e em caráter estadual, a Deliberação n02/03 (PARANÁ, 2003) sobre normas para a Educação Especial, modalidade da Educação Básica, e o Parecer nº 07/14 (PARANÁ, 2014), sobre pedido de análise e parecer da Proposta de Ajustes na Organização das Escolas de Educação Básica, na Modalidade Educação Especial. 
As Diretrizes Nacionais para Educação Especial na Educação Básica (BRASIL, 2001, p. 33) fixam que essa modalidade de ensino tem como principal justificativa e intuito oferecer uma amplitude de recursos, apoios e estratégias "de caráter mais especializado, que proporcionem ao aluno meios para acesso ao currículo". Nessa perspectiva, o trabalho pedagógico deve proporcionar formas e objetivações intencionais para aprendizagem do aluno por meio de metodologias que agreguem recursos e estratégias adequados ao sucesso escolar. Assim, pressupõe a escola com um projeto pedagógico que atenda ao princípio da flexibilização para acesso ao currículo por meio de condições adequadas e qualitativas que favoreçam ao progresso escolar.

No que diz respeito à organização do atendimento em escolas especiais, as diretrizes assinalam a necessidade da criação e uso de medidas alternativas de educação e com recursos materiais e profissionais especializados para que assim a escola especial assegure o desenvolvimento integral dos cidadãos. Consequentemente, a prática pedagógica sistematizada com esses elementos exige do docente a capacidade de análise e avaliação para organização do ensino com vista à aprendizagem do aluno.

Portanto, tais elementos indicados acima pontuam a profissionalidade exigida no processo de formação docente. No que tange as categorias de profissionalização para Educação Especial há destaque para a formação continuada (professores especializados em Educação Especial) e profissionalismo, em especial, o domínio de conteúdos e métodos de ensino direcionado as peculiaridades e especificidades dos alunos público-alvo da Educação Especial.

Instrumentalizados pelas diretrizes (2001), as normas do Paraná - Deliberação nº 02/03 e Parecer n 07/14 - para as Escolas de Educação Básica na modalidade de Educação Especial reafirmam os elementos supracitados e analisados acima. Destacamos que o papel desta escola é prover e promover um ensino que atenda às necessidades educativas dos alunos com NEE, a fim que ele aprenda, ou seja, tenha acesso ao currículo, que, por sua vez, representa um conjunto de saberes mínimos para plena participação social como cidadão.

Em seu artigo 20, a Deliberação $n^{\circ}$ 02/03 (PARANÁ, 2003) assegura que as escolas especiais, como requisitos mínimos quanto aos docentes e trabalho pedagógico, devem: ter professores habilitados ou especializados em Educação Especial e, fornecer "ajuda e apoio intensos e contínuos e flexibilizações e adaptação curricular tão significativa que a escola regular não tenha conseguido prover" (p. 6).

No Parecer $n^{0}$ 07/14 sublinhamos, por caráter de relevância à nossa pesquisa, que, por meio de um trabalho pedagógico desenvolvido por profissionais especializados, há durante a 
formação continuada desse professor a necessária apropriação de "estudos sobre as características das deficiências e concepções pedagógicas, bem como acompanhando as práticas nas escolas" (p. 4), que lhe fornecerá subsídios teóricos e práticos para que possa organizar as adaptações e flexibilizações diante do currículo, e até mesmo analisar "a possibilidade de prolongamento de permanência do educando no ano ou no ciclo escolar em que está matriculado" (p. 4), para que assegure a aprendizagem efetiva dos conteúdos.

Todas essas sinalizações nos documentos norteadores sobre o papel da escola especial e do professor que atua nessa instituição reforçam o caráter profissionalizante da profissão docente que agrega um processo de constituição de sua profissionalidade, bem como suas categorias: profissionalização e o profissionalismo.

Após tais discussões propostas destacando os conceitos de profissionalismo, profissionalidade e profissionalização diante o papel da escola e do trabalho pedagógico na Educação Especial, apresentamos nas próximas seções os procedimentos metodológicos empregados na pesquisa de campo e os entendimentos dos professores que atuam na Escola de Educação Básica na modalidade de Educação Especial acerca de seu trabalho pedagógico junto aos alunos com deficiência.

\section{ENCAMINHAMENTOS METODOLÓGICOS}

Empregamos, inicialmente, a pesquisa bibliográfica para destacar o papel da escola e do trabalho docente na Educação Especial, que consistiu em um levantamento de dados, nos colocando em contato direto com o que foi escrito sobre o tema e assunto desta pesquisa (LAKATOS; MARCONI, 2005).

Nesse momento, pontuamos os encaminhamentos metodológicos adotados na pesquisa de campo quanto à coleta e análise dos dados empíricos coletados, visando à descrição de um determinado assunto procurando conhecer e estabelecer a relação entre o referencial teórico e os dados empíricos (LAKATOS; MARCONI, 2005).

Elencamos como sujeitos da pesquisa professores que atuam em duas escolas de Educação Básica na modalidade de Educação Especial, os quais reportaremos com a letra P. Estas escolas foram delimitadas aleatoriamente em um município do norte do Paraná nomeadas como A e B. Sendo assim, denominaremos PA e PB, seguidos da numeração aleatória dos questionários respondidos (PA1, PA2,.. PB1, PB2,...). Usamos como instrumento de coleta de dados um questionário contemplado com perguntas abertas e fechadas sobre o perfil dos informantes e percepções dos professores quanto a: sua atividade 
pedagógica; aspectos necessários para ser um professor e avaliação de sua atividade pedagógica frente ao aluno com deficiência. Esse, por sua vez, tem por objetivo "levantar informações escritas por parte dos sujeitos pesquisados, com vistas a conhecer a opinião dos mesmos sobre os assuntos em estudo" (SEVERINO, 2007, p. 125).

O questionário foi composto de sete (7) questões, sendo três (3) objetivas (múltipla escolha, fechadas) e quatro (4) subjetivas (dissertativas, abertas). As questões de 1 a 4 (três fechadas e uma aberta) referem-se à caracterização do perfil dos informantes. As questões $5 \mathrm{a}$ 7 tratam das percepções do trabalho docente na educação especial (questões abertas). Antes da aplicação deste instrumento de coleta de dados com os sujeitos de nossa pesquisa, aplicamos o questionário com dois mestrandos que já atuaram em Escolas na modalidade de Educação Especial, atividade realizada em média de 15 minutos. Dessa maneira, reavaliamos as questões elaboradas e, assim, realizamos ajustes necessários, deixando mais claros e objetivos os questionamentos presentes no instrumento de coleta de dados - questionário. Após isto, as pesquisadoras, em posse do pedido de autorização para realização de pesquisa e questionário, encaminhou o andamento da aplicação do instrumento de coleta de dados.

$\mathrm{Na}$ instituição $\mathrm{A}$ e $\mathrm{B}$, os questionários foram entregues pessoalmente a 15 professores e 10 professores, respectivamente. Obtivemos 10 questionários respondidos da instituição A e 10 da instituição $\mathrm{B}$, tendo um total de 20 questionários que passaram à análise dados e discussão dos resultados por meio do referencial teórico adotado.

\section{A PROFISSÃO DOCENTE NA EDUCAÇÃO ESPECIAL}

Esta seção expõe a análise e discussão dos dados coletados por meio do questionário aplicado a 20 professores que atuam em duas escolas de Educação Básica na modalidade de Educação Especial.

Tendo em vista os objetivos da pesquisa, as respostas coletadas com a questão 7 (Como você avalia sua atividade pedagógica frente aos alunos com deficiência?), não foram satisfatórias. Originalmente, pensou-se que, com a pergunta, coletaríamos respostas relativas à avaliação do docente sobre sua própria prática pedagógica. Mas, ao nos debruçarmos sobre o material, constatou-se que os entrevistados responderam indicando e listando conteúdos, atividades e comportamentos dos alunos, ou seja, eles interpretaram a questão como relacionada às formas de avaliação do aprendizado que o professor utiliza em sala.

Apresentamos abaixo o perfil dos docentes de Educação Especial participantes das instituições A e B referente às questões de 1 a 4 desta pesquisa, as percepções docentes sobre 
sua atividade pedagógica com o aluno com deficiência e, por fim, os aspectos considerados necessários para ser um professor de aluno com deficiência.

\section{Perfil dos docentes}

Os professores das instituições A e B participantes da pesquisa, 19 são do sexo feminino e 1 do sexo masculino com média aproximada de 47 anos de idade e média de 18 anos de exercício profissional como docente. Todos informaram ter graduação (13 em Pedagogia, 1 História, 2 Psicologia, 1 Letras e 3 em Educação Física), sendo que 9 professores, além de formação superior, possuem formação docente em nível médio. Ainda cabe mencionar que 7 possuem duas graduações e que todos os docentes são especialistas em educação especial ${ }^{3}$.

\section{Percepções docentes sobre sua atividade pedagógica com o aluno com deficiência.}

A partir da pergunta 5 "Quando você trabalha com os alunos com deficiência, quais motivos norteiam suas atividades?", os docentes entrevistados nessa pesquisa apontaram como principais motivos/objetivos que norteiam sua prática pedagógica: (i) necessidades e dificuldades dos alunos, (ii) conteúdos propostos no currículo, (iii) finalidade das atividades (aspecto motor, cognitivo e afetivo), (iv) aprendizagem e desenvolvimento do aluno com deficiência. Para representar as respostas obtidas, utilizamos o gráfico abaixo (Gráfico 1) que indica a porcentagem de citação desses motivos nas respostas dos 20 docentes participantes desta pesquisa. Isto é, a porcentagem representa a relação com o número total de participantes.

\footnotetext{
${ }^{3}$ Tal formação de especialista atende a exigência de formação mínima para atuação em instituição de ensino na modalidade de Educação Especial (PARANÁ, 2003).
} 


\title{
Gráfico 1: Motivos docentes para atividade pedagógica com o aluno com deficiência
}

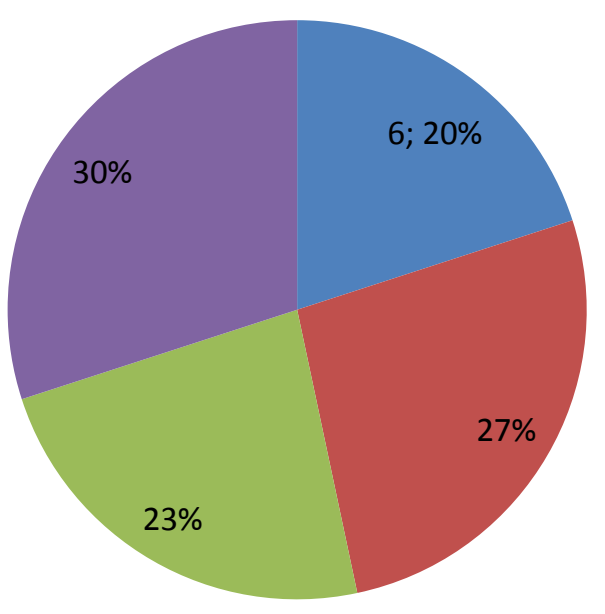

\author{
Necessidades e dificuldades dos \\ alunos \\ Conteúdos propostos no \\ currículo \\ Finalidade das atividades \\ (aspecto motor, cognitivo e \\ afetivo) \\ Aprendizagem e \\ desenvolvimento do aluno com \\ deficiência
}

Fonte: Elaborado pelos autores.

Retomando as ideias de Tozoni-Reis (2010), a escola surge na modernidade para cumprir a tarefa de satisfazer a necessidade de formação humana, isto é, ensinar os conhecimentos construídos social e culturalmente pela humanidade. Assim, a figura do professor emana da especialização do ato de ensinar: uma pessoa com formação e capacitação específica para tal ação sistematizada e intencional.

Paralelamente, visualizamos que a atividade pedagógica desses professores é motivada, principalmente, pela aprendizagem e desenvolvimento do aluno com deficiência totalizando $45 \%$ das respostas obtidas com 20 docentes da escola A e B. Este motivo está atrelado a sua atividade principal que é ensinar, consequentemente, com o objetivo de que sua ação educativa leve o aluno a se apropriar dos conteúdos determinados pelo currículo da instituição impulsionando seu desenvolvimento e aprendizagem.

Essa preocupação com o ensino e a aprendizagem do aluno pode ser evidenciado, por exemplo, pelas respostas dos docentes abaixo:

PA2: O aluno é o foco principal. Cada atividade realizada, somos motivadas a beneficiar o aluno seja na parte pedagógica, psicomotora ou estimulação de vários níveis. Nunca pensar que a condição do aluno possa restringi-lo, pois o mesmo possui os direitos de receber os ensinamentos os quais lhe ajudarão.

PA9: Ao trabalho com os alunos sempre me utilizo de uma criteriosa avaliação que revele os conhecimentos já adquiridos de meus alunos e o que eles precisam desenvolver, visto que a partir dessa avaliação tenho condições de construir um 
plano de trabalho docente que atenda a necessidades individuais de cada um, trabalhando especificamente o que aluno precisa para desenvolver seu potencial.

PB4: No caso trabalho com EJA na Educação Especial, trabalhando todos os conteúdos, principalmente, sua independência e autonomia.

Desse modo, apreendemos pelas percepções dos professores que sua prática pedagógica está voltada para organização do ensino, em que ele deve promover a mediação do conteúdo/conhecimento selecionado do currículo para apropriação do aluno com NEE. Os docentes apresentam como motivos principais para a ação educativa com alunos com deficiência sua responsabilidade com a promoção de condições e oportunidades objetivas à aprendizagem.

\section{Aspectos considerados necessários para ser um professor de aluno com deficiência}

Tendo em vista a docência e a profissionalidade docente, a questão 6 "O que você considera ser necessário para que alguém seja um professor de alunos com deficiência?", teve por objetivo identificar requisitos para atuação profissional na Educação Especial a partir da percepção de professores que possuem subsídios teóricos (formação especialista) e práticos (formação em serviço e tempo exercício do magistério nessa modalidade - média de 18 anos).

Analisando as respostas dos professores participantes dessa investigação, evidenciamos que $20 \%$ dos questionários apresentaram apenas elementos correlacionados aos aspectos da profissionalidade docente. Em contraponto, $80 \%$ dos questionários apresentaram falas que atribuíam um sentido de intimidade e de pessoalidade para sua atuação profissional na Educação Especial, distante dos aspectos de profissionalidade, de profissionalização e de profissionalismo indicados por Libâneo (2004). Nessas falas, aparecem sentimentos de ordem privada como elementos imprescindíveis à Educação Especial e no exercício da docência destes profissionais. Isso demonstra uma contradição com as respostas obtidas na questão 5 do questionário (rever Gráfico 1) em que os docentes ressaltam o caráter profissional de sua ação pedagógica. Abaixo (ver Quadro 1), elaboramos uma tabela que ilustra as percepções enunciadas pelos docentes e número total de menções de cada aspecto nos questionários. 
Quadro 1: Aspectos considerados necessários para ser um professor de aluno com deficiência

\begin{tabular}{|c|c|c|c|}
\hline $\begin{array}{c}\mathbf{N}^{0} \text { de } \\
\text { menções }\end{array}$ & Profissionalidade & $\begin{array}{c}\mathbf{N}^{0} \text { de } \\
\text { menções }\end{array}$ & Pessoalidade \\
\hline 5 & $\begin{array}{c}\text { Formação inicial } \\
\text { profissional }\end{array}$ & 6 & Dom/vocação \\
\hline 5 & $\begin{array}{c}\text { Formação continuada/ } \\
\text { cursos de } \\
\text { aperfeiçoamento }\end{array}$ & 8 & Paciência \\
\hline 7 & $\begin{array}{c}\text { Pesquisar e estudar } \\
\text { constantemente métodos } \\
\text { e materiais para seu } \\
\text { trabalho pedagógico }\end{array}$ & 6 & Amor \\
\hline 6 & $\begin{array}{l}\text { Compromisso e } \\
\text { dedicação com a } \\
\text { profissão }\end{array}$ & 5 & Afetividade/perseverança \\
\hline 4 & $\begin{array}{l}\text { Entendimento do papel } \\
\text { de sua ação pedagógica } \\
\text { para aprendizagem do } \\
\text { aluno com deficiência }\end{array}$ & & \\
\hline Total: 27 & & Total: 25 & \\
\hline
\end{tabular}

Fonte: Elaborada pelos autores.

O número total de menções dos elementos de caráter profissional (27) e pessoal (25) são quase equivalentes, indicando que os docentes estabelecem uma relação de dependência destes aspectos para ser professor na Escola de Educação Básica na modalidade de Educação Especial. Portanto, fica clara uma invasão de temas privados no domínio de uma atuação que se esperaria mais formalizada, ou seja, recorrendo a valores e critérios técnicos relativos ao exercício de uma profissão.

As menções de caráter pessoal (dom/vocação, paciência, amor, afetividade/perseverança) minimizam a importância e exigência da formação profissional dando lugar para aspectos que esvaziam e descaracterizam a profissionalidade docente e os requisitos de profissionalização e profissionalismo existentes.

Alertamos para a resposta dada pelo PB5 que sinaliza aspectos de caráter pessoal como prioridade, em detrimento da relevância primordial dos aspectos de caráter relacionados à profissionalidade, e ainda, julgando necessário ambos os aspectos para atuação docente junto aos alunos com deficiência. 
PB5: Em primeiro plano a pessoa gostar de alunos especiais, não ter medo, ter paciência e não ter nojo. Depois formação acadêmica especifica para saber lidar com as deficiências e suas características.

Podemos confirmar que esses elementos categorizados anteriormente (Quadro 1) assinalam os equívocos e confusão de tratar requisitos da profissionalidade pedagógica com elementos do caráter de pessoalidade ligado à afinidade pessoal e afeto com o outro.

Sublinhamos na fala do PB5 a expressão "não ter nojo", o que indica uma preocupação com a relação mais próxima ao aluno. No entanto, essa fala configura um aspecto ressaltado na área da Educação Especial como um pré-requisito para atuação profissional.

De acordo com Rossato e Leonardo (2011, p. 2) "a sociedade, de modo geral, enfrenta enormes dificuldades para lidar com o que é diferente, isto é, com tudo aquilo que se afasta dos padrões estabelecidos como normais". Por isso, o processo educativo junto a alunos público-alvo da Educação Especial representa uma barreira atitudinal dentro do sistema educacional (SILVA; REIS, 2011).

Conforme Libâneo (2004), a profissionalidade exige o domínio de conhecimentos e técnicas relativas à ação intencional e sistematizada, ou seja, uma ação especializada com determinado fim.

Nesse sentido acreditamos que quando observamos que os profissionais misturam, exigem e apontam, como requisito necessário para atuação de sua profissão, elementos da esfera pessoal na esfera de sua atuação profissional, esvaziam a finalidade específica dessa relação. Isso esvazia também o papel profissional e as exigências formais e especializadas de sua formação. Por essa razão, o modo pelo qual professores, participantes desta pesquisa, transferem exigências de domínio profissional a uma relação de pessoalidade, o sentido de sua prática pedagógica com os alunos com deficiência apresenta-se como uma extensão da intimidade e emotividade de suas relações privadas e familiares.

\section{CONSIDERAÇÕES FINAIS}

Para finalizar este artigo, retomamos a questão investigativa: Quais as compreensões de docentes da escola de Educação Básica na modalidade de Educação Especial sobre o seu trabalho com os alunos com deficiência? 
Depreendemos que, diante sua prática pedagógica, os professores participantes da pesquisa de campo destacaram o papel de mediadores para a aprendizagem do aluno com deficiência, porém elencaram como requisitos necessários para atuação nessa modalidade de ensino aspectos de suas relações privadas, o que os distancia do papel da escola e do trabalho pedagógico na Educação Especial, com vistas à constituição de uma profissionalidade docente.

Evidenciamos que o trabalho pedagógico nas Escolas de Educação Básica na modalidade de Educação Especial exige conhecimento e domínio de métodos e técnicas que promovam a aprendizagem dos alunos público-alvo da Educação Especial. Esses requisitos são elencados e determinados pela legislação pertinentes que considera o processo educativo como aquele sistematizado e intencionalmente promovido para que haja apropriação dos conteúdos e acesso ao currículo.

Tais requisitos são denominados de saberes docentes que são elementos que constituem a dimensão do profissional docente. São conhecimentos de dimensão teórica e prática que são construídos e se constroem na formação inicial e continuada, conhecimentos teóricos e encaminhamentos práticos que alicerçarão a profisssionalização do ensino e profissionalismo docente.

Compreendemos que esses conjuntos de saberes da docência, durante a formação inicial e contínua, subsidiarão a organização do ensino a fim de que o aluno aprenda. Essa sequência de aulas, conteúdos, atividades permitirá trabalhar em uma mediação qualitativa para promover as condições necessárias e adequadas para a apropriação do conhecimento pelo aluno, seja ele com ou sem deficiência.

No que se refere à profissionalidade, profissionalismo e profissionalização e sua constituição pelos professores, é necessário que os saberes/requisitos sejam mobilizados/construídos na prática pedagógica da formação e das salas de aula. Desse modo, envolvendo não só uma dimensão epistemológica (natureza dos saberes envolvidos), mas também uma dimensão política, que poderá contribuir para a construção de uma identidade profissional dos professores, indispensável para a consolidação da profissionalidade docente.

Acreditamos que essa temática não é findável e nem passível de generalização, e dessa forma, a partir dessa investigação, almejamos desenvolver novos estudos no que diz respeito às exigências formais à pessoalidade de professores que atuam no ensino regular na perspectiva da inclusão. Dessa forma, poderemos identificar os aspectos elencados pelos docentes na compreensão de sua atuação pedagógica junto a alunos com e sem deficiência. 


\section{REFERÊNCIAS}

BOURDIEU, P. A escola conservadora: as desigualdades frente à escola e à cultura. Paris: Rewe française de sociologie, 1966. Tradução Aparecida Joly Gouveia. In: Educação em Revista, Belo Horizonte, n. 10, p.3-15, dez/1989. Disponível em:

$<$ http://disciplinas.stoa.usp.br/pluginfile.php/347751/mod_resource/content/1/Boudieu_escola \%20conservadora.pdf $>$. Acesso em: 14 jan.2016.

BOURDIEU, P.; PASSERON, J. C. Os herdeiros: os estudantes e a cultura. Florianópolis: UFSC, 2013.

\section{BRASIL. Declaração de Salamanca e Princípios, Políticas e Práticas na Área das} Necessidades Educativas Especiais. Brasília: MEC, 1994. Disponível em:

$<$ http://portal.mec.gov.br/seesp/arquivos/txt/salamanca.txt>. Acesso em: 14 jan. 2016.

BRASIL. Lei no 9.394/96, que institui as Diretrizes e Bases da Educação Nacional, em 20 de dezembro de 1996. Brasília: MEC, 1996. Disponível em:

$<$ http://www.planalto.gov.br/ccivil_03/leis/19394.htm>. Acesso em: 14 jan. 2016.

BRASIL. Resolução n $\mathbf{n}^{\mathbf{0}}$ 02/2001, que institui as Diretrizes Nacionais para a Educação Especial na Educação Especial. Brasília: CNE/CEB, 2001.

FERREIRA, R. M. Sociologia da Educação. São Paulo: Moderna, 1993.

KRUPPA, S. M. P. A educação como tema da sociologia. In: Sociologia da educação. São Paulo: Cortez, 1991. (Série formação de professores).

LIBÂNEO, J. C. Organização e gestão da escola: teoria e prática. 5. ed. Goiânia: Alternativa, 2004.

NOGUEIRA, C. M. M.; NOGUEIRA, M. A. A sociologia da educação de Pierre Bourdieu: limites e contribuições. Revista educação e sociedade. Campinas, v. 23, n. 78, p. 15-35, abr. 2002.

PARANÁ. Deliberação n02/03, sobre normas para a Educação Especial, modalidade da Educação Básica para alunos com necessidades educacionais especiais, no Sistema de Ensino do Estado do Paraná. Curitiba: SEED/CEE, 2003.

PARANÁ. Diretrizes Curriculares da Educação Especial para a construção de currículos inclusivos. Curitiba: SEED, 2006. Disponível em:

$<$ http://www.educadores.diaadia.pr.gov.br/arquivos/File/diretrizes/dce_edespecial.pdf $>$. Acesso em: 14 jan. 2016.

PARANÁ. Parecer n⿳0 07/14, sobre pedido de análise e parecer da Proposta de Ajustes na Organização das Escolas de Educação Básica, na Modalidade Educação Especial, para oferta da Educação Infantil, do Ensino Fundamental - Anos iniciais ( $1^{\circ}$ e $2^{\circ}$ anos), da Educação de Jovens e Adultos - Fase I e da Educação Profissional, aprovada pelo Parecer CEE/CEB n ${ }^{\circ}$ 108/10, de 11/02/10. Curitiba: SEED/CEE/CEIF/CEMEP,2014

PARANÁ. Resolução n⿳ 3600/2011, que autoriza a alteração do nome das escolas de educação especial para escolas de educação básica, na modalidade de educação especial. 
Curitiba: SEED/CEE, 2011. Disponível em:

$<$ http://www.educacao.pr.gov.br/arquivos/File/coletaneas/coletanea2011.pdf $>$. Acesso em: 14 jan. 2016.

PARCHEN, M. J. Profissionalidade docente e as condições da docência precarizadas. Curitiba: SEED/PDE, 2008.

ROSSATO, Solange P. M.; LEONARDO, Nilza S. T. A deficiência intelectual na concepção de educadores da Educação Especial: contribuições da psicologia histórico cultural. Revista Brasileira de Educação Especial, vol.17, n.1, Marília, Jan/Abril. 2011. Disponível em: <http://dx.doi.org/10.1590/S1413-65382011000100006 > Acesso em: 12 jan. 2016.

SILVA, Lívia R. de S.; REIS, Marlene B. de F. Educação Inclusiva: o desafio da formação de professores. Inhumas: UEG/REVELI, v. 3, n.1, março, 2011. (p. 07-17). Disponível em: $<$ http://www.ueginhumas.com/revelli/revelli5/numero3_n1/revelli.v3.n1.art01.pdf $>$ Acesso em: 12 jan. 2016.

TOZONI-REIS, M. F. C. A contribuição da Sociologia da educação para compreensão da educação escolar. São Paulo: UNESP, 2010. Disponível em:

$<$ http://www.acervodigital.unesp.br/bitstream/123456789/169/3/01d09t03.pdf $>$. Acesso em: 14 jan. 2016.

\section{OS AUTORES}

Jacqueline Lidiane de Souza Prais é Mestre em ensino pela Universidade Tecnológica Federal do Paraná - Campus Londrina. Graduada em Pedagogia pela Universidade Estadual do Norte do Paraná - Campus de Cornélio Procópio (UENP/CCP). Especialista em Educação Especial Inclusiva e em Políticas Públicas para a Educação, ambas pela UENP/CCP. Atualmente é doutoranda em educação na Universidade Estadual de Londrina (UEL). E-mail: jacqueline lidiane@hotmail.com

Juliana Irani Villanueva dos Reis é Mestre em ensino pela Universidade Tecnológica Federal do Paraná - Campus Londrina. Especialista em Educação Especial e Estudos Adicionais na Área da Deficiência Mental - Faculdade de Ciências e Letras de Cornélio Procópio. Atualmente integra a equipe de Educação Especial do Núcleo Regional de Educação de Londrina, respondendo pelas áreas da Deficiência Intelectual, Deficiência Física Neuromotora e Altas Habilidades/Superdotação.

E-mail:: professorajulianareis@gmail.com

Daniel Guerrini é Doutor em Sociologia. Graduado em Ciências Sociais pela Universidade Estadual de Londrina, Mestre em Sociologia pelo Programa de Pós-Graduação em Sociologia da UFRGS. Atualmente é docente no Departamento Acadêmico de Ciências Sociais e Humanas, da Universidade Tecnológica Federal do Paraná - Câmpus Londrina.

E-mail: danielguerrini@utfpr.edu.br 